\title{
The Effect of Machining Parameters on Weight Removal in Chemical Machining of Titanium Alloy
}

\author{
Abbas Fadhil Ibrahim, Dunia Adnan Ghullam \\ Department of Production Engineering and Metallurgy, University of Technology, \\ dunia.adnan9@yahoo.com
}

\begin{abstract}
:
Chemical machining (CHM) processes are one of the non-conventional machining processes the material removal occurs when the machined part contact with a strong chemical etchant solution. This study aiming to study the influences of machining time, machining temperature and the concentration of the used etchant solution on the weight removal of chemically machined titanium alloy, in this study two different etchant concentration of mixture acids consist of hydrofluoric acid (HF) mixed with nitric acid (HNO3) in specific quantities are used, the first etchant concentration consist of $(9$ vol.\% HF , 14 VOL.\% HNO3 in 77 vol.\% distilled water) the second concentration (12 vol.\% HF, 16 vol.\% HNO3 in 72 vol.\% distilled water) to chemically machine eight specimens of $(30 \times 10 \times 1) \mathrm{mm}$ size by using four level of machining time (4, 6, 8 and 10) $\mathrm{min}$ and four level of machining temperature $\left(35,40,45\right.$ and 50) $C^{\circ}$ for both concentrations as a machining conditions. The results show that the weight removal increased with the increasing of the time, temperature and the concentration of the used etchant.
\end{abstract}

Key words: CHM, weight removal, Titanium, etchant, parameters.

Paper History:Received:5-4-2018; Accepted :14-8-2018)

\section{Introduction:}

Machining processes are divided into two types: conventional and nonconventional machining processes. In conventional machining processes different tools (single or multipoint tools) widely used to remove material form the machined parts and forms chips to produce different parts. The nonconventional machining processes are widely used to produce complex shapes and precision parts such as different parts of aerospace, electronics and automotive parts. Moreover, the chemical machining methods are widely used to produce microcomponents for different manufacturing operations such as micro-electromechanical systems (MEMS) and semiconductor industries. Chemical machining is one of nonconventional processes in which controlled chemical dissolution used to machine work part material by immersing it in strong acidic or alkaline chemical etchant. Specific coatings called maskants are used to protect areas where the metal is not to be removed [1].

The main types of chemical machining: chemical milling it is used for pockets, contours, overall metal removal; chemical blanking for etching through thin sheets; photochemical machining (PCM) for etching different material by using photosensitive resists in microelectronics; chemical or electrochemical polishing where weak chemical reagents are used for polishing or deburring and chemical jet machining where a single chemically active jet is used. The most important two materials used in chemical milling process are etchant and maskant. Etchants are acid or alkaline solutions kept with controlled ranges of chemical composition and temperature. Maskants are specially designed elastomer or polymer products which have high chemical resistant to the used etchants. Basically all metals used in aerospace and metalworking industries can be chemically milled [2]. Table (1) below shows the etchants and the maskants that used for chemical machining for different materials [3].

Table (1): Etchants and maskants for different materials

\begin{tabular}{|c|c|c|c|c|}
\hline Work-piece & Etchant & Maskant & Etch rate $\mathbf{m m}$ /min & Etch factor \\
\hline \multirow{2}{*}{ Aluminum } & $\mathrm{FeCl3}$ & $\begin{array}{c}\text { Polymers } \\
\text { polymers }\end{array}$ & $\begin{array}{c}0.013-0.025 \\
0.020-0.030\end{array}$ & $1.5-2.0$ \\
\hline \multirow{2}{*}{ Magnesi-um } & $\mathrm{HNO} 3$ & Polymers & $1.0-2.0$ & 1.0 \\
\hline \multirow{2}{*}{ Copper } & $\mathrm{FeCl3}$ & Polymers & $\begin{array}{l}2.0 \\
1.2\end{array}$ & $2.5-3.0$ \\
\hline \multirow{2}{*}{ Steel } & $\mathrm{CuCl3}$ & $\begin{array}{l}0.025 \\
0.025\end{array}$ & 2.0 \\
\hline \multirow{2}{*}{ Titanium } & $\mathrm{FeCl3}$ & Polymers & 0.025 & \multirow{2}{*}{1.0} \\
\hline Nickel & $\mathrm{HF}: \mathrm{HNO} 3$ & polymers & $0.13-0.038$ & $1.0-3.0$ \\
\hline Silicon & $\mathrm{FeCl3}$ & polyethylene & Very slow & \\
\hline
\end{tabular}


The etchant that used in chemical milling of titanium alloys is hydrofluoric acid mixed with nitric acid; the titanium has an excellent corrosion resistance in many acid media, except in hydrofluoric acid in which it dissolves according to the equation (1) [4]:

$$
\mathrm{Ti}+3 H F^{-} \rightarrow T i^{+3}+3 / 2 H_{2}+3 F^{-}
$$

$\mathrm{Ti}^{+3}$ Being further oxidized by oxygen of the atmosphere it is very slow by using hydrofluoric acid itself. The use of pure hydrofluoric acid as an etchant solution for Titanium must be avoided due to the formation of hydride at the surface of the machined metal and result embrittlement. Therefore the etching of titanium is done in a mixture of nitric and hydrofluoric acids in water. The concentrations of the acid mixture can be optimized to get a suitable etching rate without hydrogen pick-up by the metal, Hydrofluoric-nitric etching solutions are known to be depleted with time, as a result of consumption of the acids, which slow down the etch rate of titanium alloy [4].

The chemical machining operations are affected by many parameters, the main effective parameters: the type of etchant solution and its concentration, the maskant and its application, the machining temperature, machining time, and the previous cold working of the part to be machined. Many parameters have direct effect on the chemical machining operation and on the properties of the machined parts and machining rate or weight removal of the machined parts, production tolerance, and surface finish [5].

Rui Neto, Teresa Duarte in (2017): Studied two different acid solutions for chemical machining of titanium aluminide. solution one consist of (4.5 vol.\% HF, 7.5 vol.\% HNO3, 5 vol.\% Erkantol and 83 vol.\% H2O), solution two consist of ( 2 vol.\% HF, 4 vol.\% H2SO4, 3.5 vol.\% $\mathrm{NaCl}$ and 90.5 vol.\% $\mathrm{H} 2 \mathrm{O}$ ), the machining temperature $35 C^{\circ}$ for both solutions. They improved that the best solution for chemical milling of titanium aluminide alloy is solution two because they get lower surface roughness. But this solution provide a lower metal removal rate than solution one but when increase the machining time and lor the temperature the metal removal rate can be increase too [6]. Andrew Labak in (2010): studied different types of etchant solutions for etch forged titanium they improved that hydrofluoric acid had the highest etch rate over (6) minutes. The machining temperature had a strong effect on the etching rate for all solutions. To get the best results the solutions temperature should be between (110-140) degrees Fahrenheit. For all solutions the mass removed in the second cycle, after a rinse of the machined part, was more than the mass removed in the first cycle [7]. Roy matsuhash, Kazuhiro Takahash in (2002): studied the effect of machining time, nitric acid (HNO3) and hydrofluoric acid (HF) concentration on the corrosion loss of titanium. They found that the corrosion loss of titanium increases with the increasing of machining time, the increasing of (HF) concentration and the increasing of machining temperature. The effect of the $\mathrm{HNO} 3$ concentration on corrosion loss is small [8].

\section{Experimental work:}

The titanium alloy, maskant materials, and the etchant that used in this study:

The chemical composition of the titanium alloy that used in this study showed in the table (2) below.

Table (2): Chemical composition of the titanium alloy

\begin{tabular}{|c|c|c|c|}
\hline $\mathrm{Al}$ & $2.56 \%$ & $\mathrm{Sn}$ & $\begin{array}{c}\text { Less than } \\
0.0005 \%\end{array}$ \\
\hline $\mathrm{V}$ & $\begin{array}{c}\text { Less than } \\
0.0037 \%\end{array}$ & $\mathrm{Ni}$ & $0.031 \%$ \\
$\mathrm{Cr}$ & $0.0283 \%$ & $\mathrm{Si}$ & $0.031 \%$ \\
\hline $\mathrm{Cu}$ & $0.354 \%$ & $\mathrm{Zr}$ & $0.0148 \%$ \\
\hline $\mathrm{Fe}$ & $0.106 \%$ & $\mathrm{Pd}$ & $0.005 \%$ \\
\hline $\mathrm{Mn}$ & $1.28 \%$ & $\mathrm{Ru}$ & $0.0233 \%$ \\
\hline $\mathrm{Mo}$ & $0.036 \%$ & $\mathrm{~W}$ & $\begin{array}{c}\text { Less } \\
\text { than } 0.01 \%\end{array}$ \\
\hline $\mathrm{Nb}$ & $0.0519 \%$ & $\mathrm{Ta}$ & $0.0484 \%$ \\
\hline \multicolumn{4}{|c|}{$\mathrm{The}$ remaining is Titanium and it is about } \\
\hline \multicolumn{4}{|c|}{$95.4161 \%$} \\
\hline
\end{tabular}


The analysis of the chemical composition was carried out in central organization for standardization and quality control (Baghdad-Iraq).

The masking material used in this study was polyester resin work as adhesive material mixed with methyl ethyl ketone peroxide work as reinforced material approximately 10:1 V\% respectively.

The chemical composition of the etchant that used in this study was hydrofluoric acid (HF) mixed with nitric acid (HNO3) in distilled water in specific percentages, the concentration of (HF) was $40 \%$ and the concentration of (HNO3) was $68 \%$.
The titanium alloy was cut into desired specimens size $(30 \times 10 \times 1) \mathrm{mm}$, all the specimens drilled with (2.5) $\mathrm{mm}$ diameter hole to carry them easily, before coating the specimens with the maskant all the specimens was washed very well with distilled water to remove the dust and grease and the dirt from the machined surface, dried it with air dryer then weighing the specimens with sensitive weighting device to determine the weight removal for the machined part, then coating one side of specimens with the maskant and the other side would represent the working area. Figure (1) represents the specimen before and after coating it with the maskant .

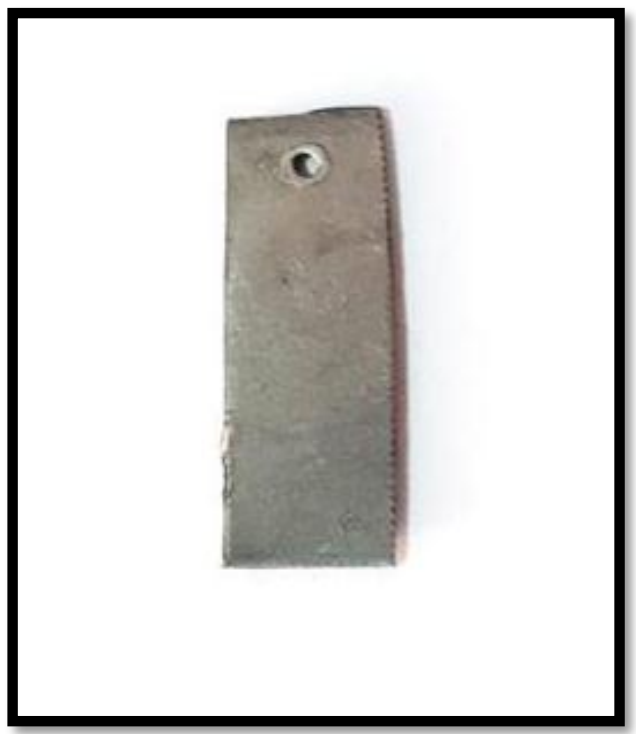

b

Figure (1): a. The specimen before coating.

b. The specimen after coating 
The etchant used in this study was a mixture of (HF) with (HNO3) in different concentration, the first concentration (9 vol.\% HF , 14 VOL.\% HNO3 in 77 vol.\% distilled water) the second concentration (12 vol.\% HF, 16 vol.\% HNO3 in 72 vol.\% distilled water), four level of machining time were used $(4,6,8$ and 10) minute, also four level of machining temperature were used (35, 40, 45 and 50) $C^{\circ}$ for both concentrations. These etchants poured into the beaker that put on the stirrer device and a suitable temperature will be selected for each experiment and the specimen will immersed for the specific time of each experiment, then the specimen rise and wash very well with distilled water and dried, figure (2) represent the setup of the chemical machining process. The maskant layer will be removed after machining by applying direct source of heat, and the weight of the specimens measured after machining process to detect the weight removal.

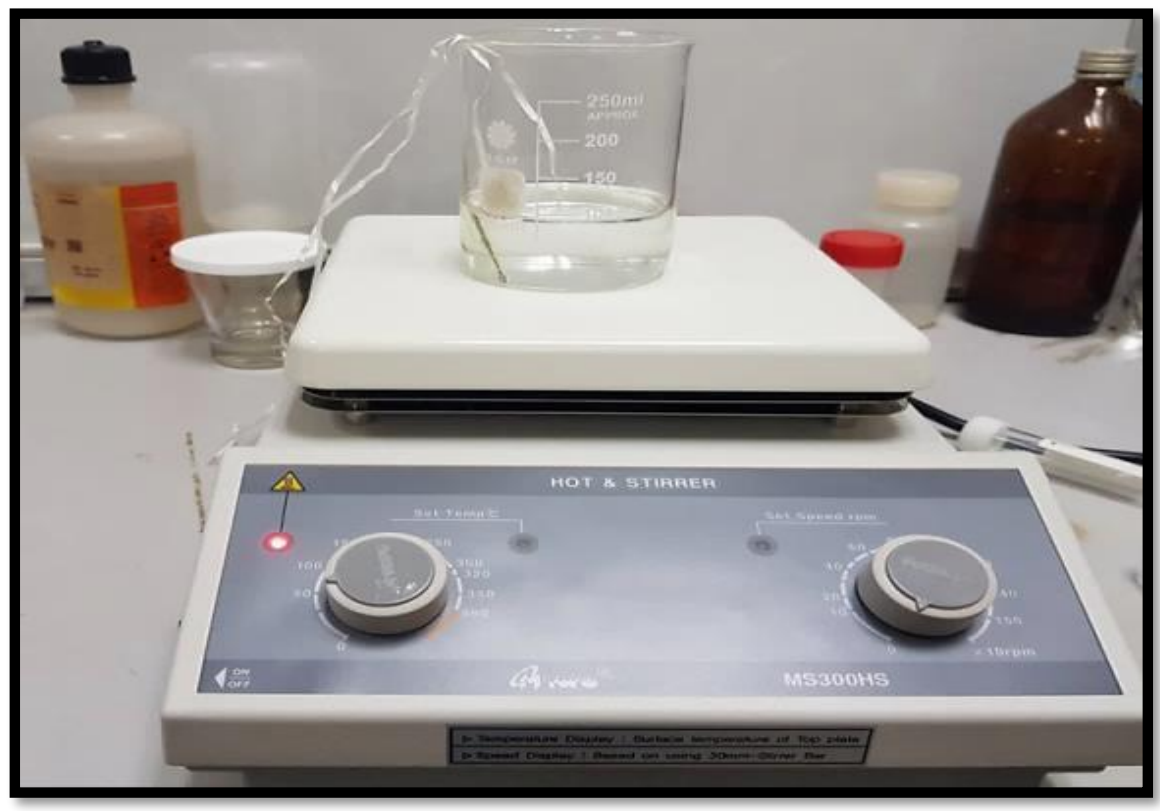

Figure (2): The setup of the process.

\section{Results and discussion:}

By using equation (2) the weight removal was determined by detecting the difference between the weight before and after machining process divided by the measuring area of each specimen because it have different areas.

Weight removal $=\frac{W b-W a}{A} \mathrm{mg} \backslash \mathrm{mm}^{2}$
$\mathrm{Wb}$ : represent the weight of the specimen before machining process $(\mathrm{mg})$

Wa: represent the weight of the specimen after machining process (mg)

A: represent the surface area of the specimen $\left(\mathrm{mm}^{2}\right)$

The table (3) below represents the measuring of the weight removal.

Table (3): Measuring of weight removal

\begin{tabular}{|l|l|l|l|l|l|}
\hline No. & $\begin{array}{l}\text { Weight } \\
\text { before }(\mathbf{m g})\end{array}$ & $\begin{array}{l}\text { Weight after } \\
(\mathbf{m g})\end{array}$ & $\begin{array}{l}\text { Wb -Wa } \\
(\mathbf{m g})\end{array}$ & Area $\left.\mathbf{( m m}^{\mathbf{2}}\right)$ & $\begin{array}{l}\text { Weight } \\
\text { removal } \\
\left(\mathbf{m g} \mathbf{m m}^{\mathbf{2}}\right)\end{array}$ \\
\hline 1 & 1420 & 1350 & 70 & 330 & 0.2121 \\
\hline 2 & 1310 & 1240 & 70 & 219 & 0.2194 \\
\hline 3 & 1360 & 1230 & 130 & 305 & 0.4262 \\
\hline 4 & 1170 & 1010 & 160 & 285 & 0.5614 \\
\hline 5 & 1370 & 1150 & 220 & 330 & 0.6667 \\
\hline 6 & 1370 & 1070 & 300 & 330 & 0.9091 \\
\hline 7 & 1160 & 740 & 420 & 279 & 1.5053 \\
\hline 8 & 1230 & 710 & 520 & 288 & 1.8056 \\
\hline
\end{tabular}


By applying the effective parameters and the chemical machining conditions to Minitab software to analyze these data with response surface methodology (RSM) and found predicts values for weight removal. Table (4) below shows the result of the analyzing operation by using (RSM).

Table (4): Data analyzed with (RSM) method

\begin{tabular}{|c|c|c|c|c|c|}
\hline No. & $\begin{array}{c}\text { Time } \\
\text { min }\end{array}$ & $\begin{array}{c}\text { Temperature } \\
\mathrm{C}^{\circ}\end{array}$ & $\begin{array}{c}\text { Concentraion } \\
\%\end{array}$ & $\begin{array}{c}\text { Weight } \\
\text { removal } \\
\left(\mathrm{mg} \backslash \mathrm{mm}^{2}\right)\end{array}$ & $\begin{array}{c}\text { Predicts } \\
\text { values } \\
\left(\mathrm{mg} \backslash \mathrm{mm}^{2}\right)\end{array}$ \\
\hline 1 & 4 & 35 & 23 & 0.2121 & 0.16675 \\
\hline 2 & 6 & 40 & 23 & 0.2194 & 0.29204 \\
\hline 3 & 8 & 45 & 23 & 0.4262 & 0.41751 \\
\hline 4 & 10 & 50 & 23 & 0.5614 & 0.54298 \\
\hline 5 & 4 & 35 & 28 & 0.6667 & 0.61974 \\
\hline 6 & 6 & 40 & 28 & 0.9091 & 1.02103 \\
\hline 7 & 8 & 45 & 28 & 1.5053 & 1.42232 \\
\hline 8 & 10 & 50 & 28 & 1.8056 & 1.82361 \\
\hline
\end{tabular}

\section{Regression equation in uncoded units:}

Predicted weight removal $=0.37-0.572 *$ time $-0.0197 *$ con. $+0.02758 *$ time $*$ con.
The regression equation used to determine the predict values of the weight removal, it is clear from equation (3) that the time has larger effect on the predict weight removal than the concentration.

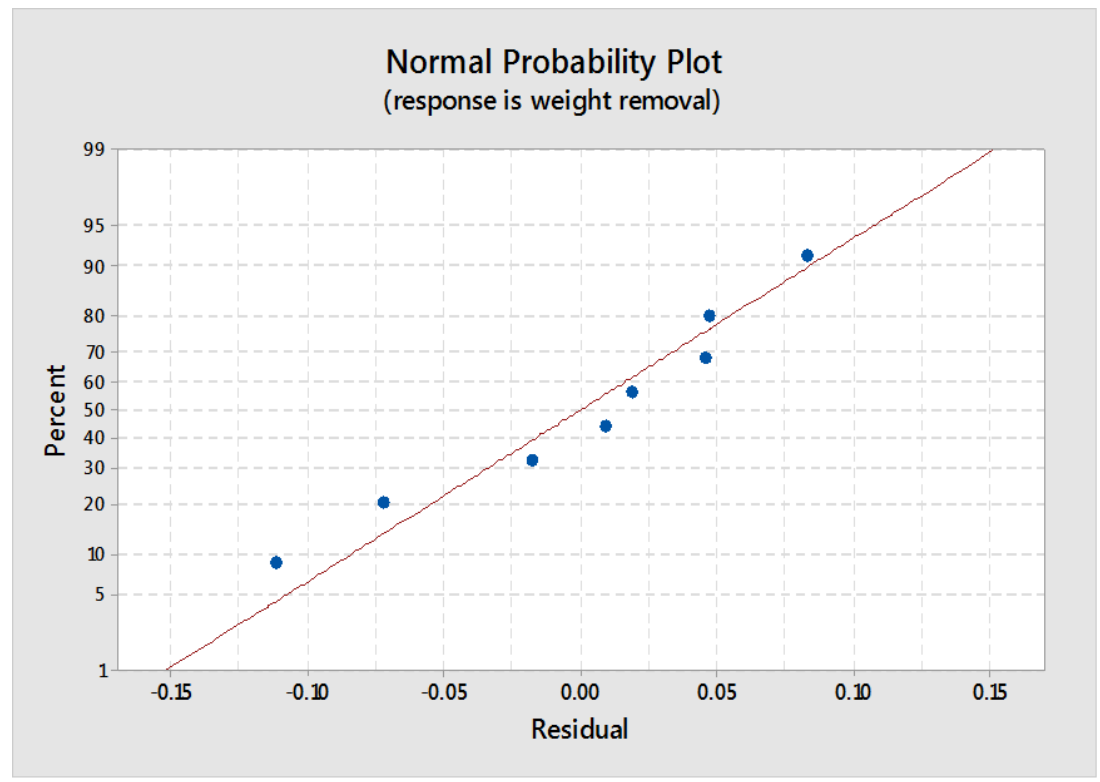

Figure (3): Normal plot for analyzed data by (RSM)

From figure (3) it is clear that all the data of probability weight removal distributed normally.

\section{Analysis of Variance:}

Analysis of variance (ANOVA) by using Minitab 2018 the analysis of variance a statistically based objective decision making tool for discover any variation in average performance of groups of items tested. The decision rather than using pure judgments, take variation in to account. The experimental design and subsequent analysis like (ANOVA) are intrinsically tied to each other. Analysis of variance breaks total variation down into responsible sources and total variation is decomposed into its suitable components. Table (5) represents the (ANOVA) for the analyzed data by (RSM) [9]. 
Table (5): Analysis of variance (ANOVA)

\begin{tabular}{|l|l|l|l|l|l|}
\hline Source & DF & Adj SS & Adj MS & F-Value & P-Value \\
\hline Model & 3 & 2.38691 & 0.79564 & 107.13 & 0.000 \\
\hline Linear & 2 & 2.19672 & 1.09836 & 147.89 & 0.000 \\
\hline $\begin{array}{l}\text { Time } \\
\text { con. }\end{array}$ & 1 & 0.69369 & 0.69369 & 93.40 & 0.001 \\
\hline $\begin{array}{l}\text { 2-Way Interact- } \\
\text { ion }\end{array}$ & 1 & 1.50303 & 1.50303 & 202.37 & 0.000 \\
\hline time*con. & 1 & 0.19019 & 0.19019 & 25.61 & 0.007 \\
\hline Error & 4 & 0.19019 & 0.19019 & 25.61 & 0.007 \\
\hline \begin{tabular}{l} 
Total \\
\hline
\end{tabular} & 7 & 2.41662 & 0.00743 & $/$ & $/$ \\
\hline
\end{tabular}

Where DF: represent the degree of freedom.

Adj-SS: represent Adjusted sum square.

Ajs-MS: represent Adjusted mean square.

From that table we can see the value of concentration larger than the value of the time that mean the concentration has larger effect on weight removal than the time.

\section{Model Summary:}

Table (6): Model summary of the analyzed data.

\begin{tabular}{|l|l|l|l|}
\hline S & R-sq & R-sq(adj) & R-sq(pred) \\
\hline 0.0861800 & $98.77 \%$ & $97.85 \%$ & $95.64 \%$ \\
\hline
\end{tabular}

Where R-sq represent ability of independent values to predict the dependent values.
The effect of temperature and time on weight removal:

The temperature had a large effect on the weight removal for chemical machining of titanium alloy the figure bellow shows the effect of temperature for concentration one $(23 \%)$ and concentration two $(28 \%)$. it is clear that when the temperature increase the weight removal increase too. Also the increasing in the concentration leads to weight removal increase.

Also the time had a great influence on the weight removal when the machining time increase the weight removal increase too, for both used concentrations. It is clear from the figure bellow that the increasing in the concentration leads to increase the weight removal. Figure (4) represents the effect of temperature and time on weight removal at concentration $23 \%$, figure (5) represents the effect of temperature and time on weight removal at concentration $28 \%$. 


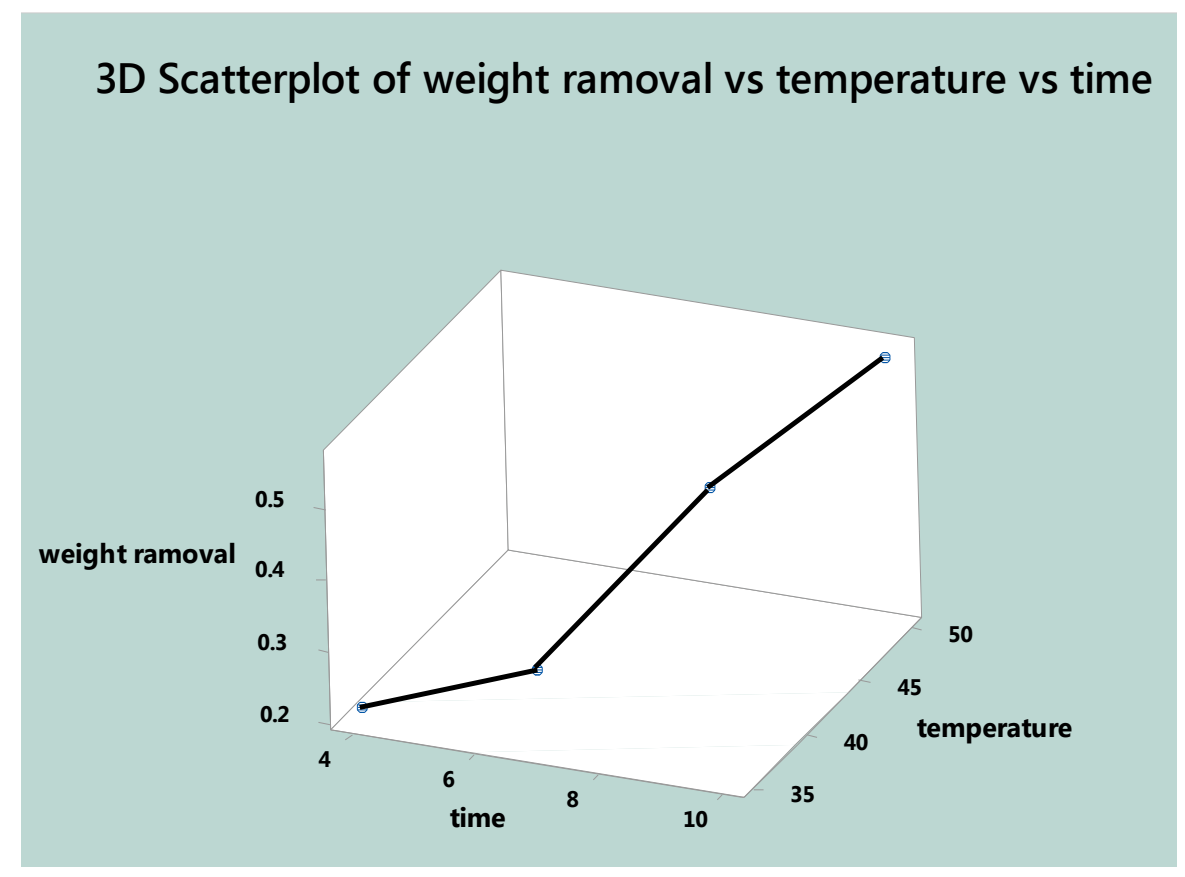

Figure (4): effect of temperature and time on weight removal at concentration $23 \%$.

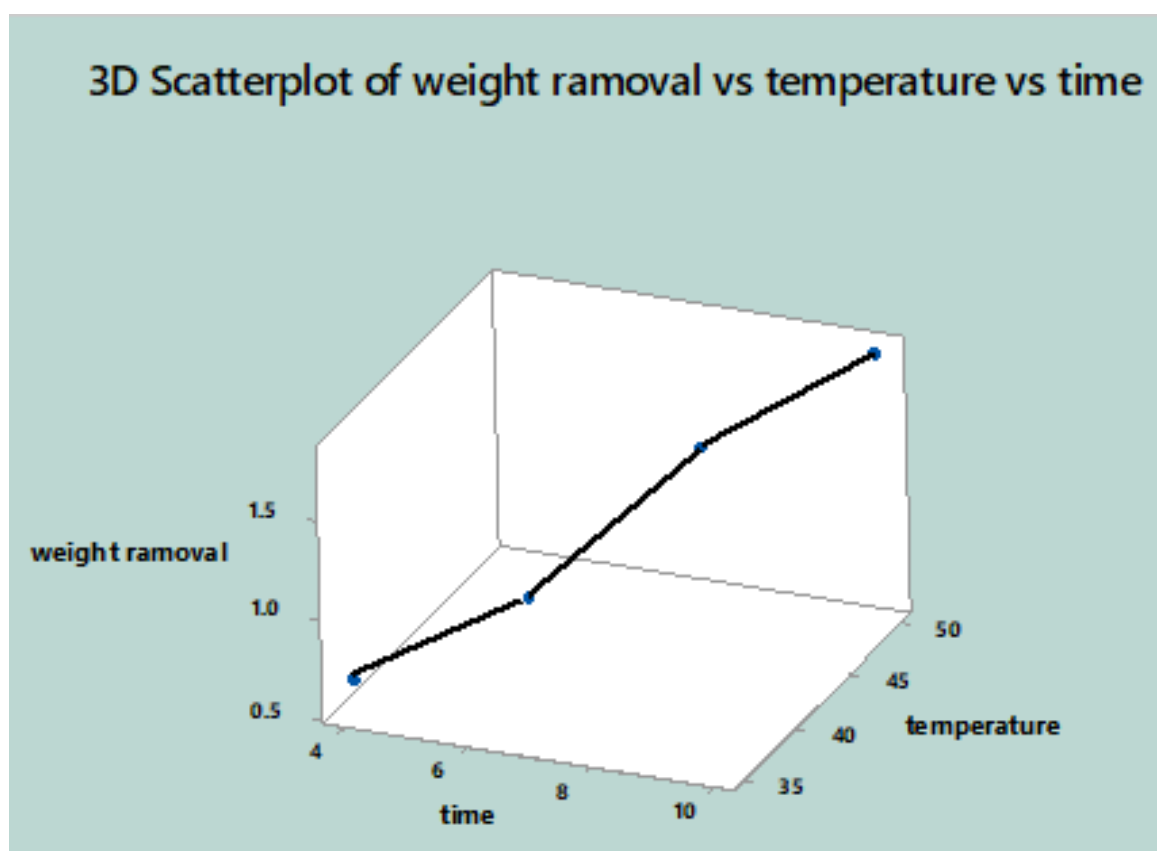

Figure (5): effect of temperature and time on weight removal at concentration $28 \%$.

\section{Conclusion:}

1-The etchant concentration, immersing time and the machining temperature have a large influence on the weight removal of the chemically machined titanium alloy. Any increasing in one of these parameters leads to increase the weight removal of the machined specimens.

2- The (R-sq) value which is Ability of Independent values to predict the Dependent values when using (RSM) was $95.64 \%$.
3- From the table of analysis of variance (ANOVA) the effect of concentration was (202.37) and it is larger than the effect of time (93.40) on weight removal.

\section{References:}

[1]. G.A. El-Awadi, T.A. Enb "Chemical Machining for Stainless Steel, Aluminum and Copper Sheets at Different Etchant Conditions" Arab Journal of Nuclear Science and Applications, 94 (2 ), (132-139) 2016. 
[2]. A. Fadaei Tehrani, E. Imanian "A new etchant for the chemical machining of St304" Journal of Materials Processing Technology 149 (2004) 404-408.

[3]. El-Hofy.H.A.-G, "Advanced Machining Processes", Black lick, OH, USA, McGraw-Hill Companies, 2005.

[4]. E. M. M. Sutrer, G. J. Goetz-Grandmont " the behavior of titanium in nitric hydrofluoric acid solutions" Corrosion Science, Vol. 30, No. 4/5, pp. 461-476, 1990.

[5]. Dr. Haydar A. H. Al-Ethari, Dr. Kadhim Finteel Alsultani, Nasreen Dakhil F." Variables Affecting the Chemical Machining of Stainless Steel 420" International Journal of Engineering and Innovative Technology Volume 3, Issue 6, December 2013.
[6]. Rui neto, Teresa Duarte "effect of chemical milling process on the surface of titanium aluminide castings" ciencia and tecnologia dos materiais 29 (2017) e40-e45.

[7]. Andrew Labak "Alternatives to Hydrofluoric Acid Etching At Wyman Gordon Company" Worcester Polytechnic Institute 2010.

[8]. Roy matsuhash, Kazuhiro Takahash "the integral rate equation of pure titanium in nitric hydrofluoric acid solutions" Nippon steel technical report no. 85 January 2002.

[9]. N.D. Misal, "Optimization Of Process Parameters In Etching During Photo Chemical Machining Process" SVERIAN Scientific, Shri Vithal Education \& Research Institute, Pandharpur, 473-484, 2005. 